\title{
Towards Other-Regarding Travel
}

\author{
R O n a I d S. B y r n e s \\ Pacific Lutheran University
}

It's a Saturday afternoon in the spring of 2003. I'm working at Sichuan University in Chengdu, China as my university's Site Director. My wife Lynn, and our daughters are grocery shopping. This is my first free afternoon since we've arrived so I decide to take a beat-up bicycle inherited from a student to an elderly, hard-working bicycle mechanic in the hope he can work some magic on it. I approach the hard-packed piece of dirt nestled between several dilapidated high-rise apartment buildings that constitutes his shop. He stands and immediately sizes up the bike. Nearby, a group of men are caught up in a spirited game of mahjong and two women try in vain to get their small dogs to fetch orange peels. The mechanic begins working on the bicycle seat, which slides up and down at the most inopportune times. Customers, with flat tires, loose pedals, and broken seats of their own, start appearing, seemingly out of nowhere. The mechanic gestures for me to sit down on an old chair right in the middle of his "shop." He stops working on my bicycle and hurriedly begins helping the other customers. Yet I feel unusually content with waiting because the setting-ordinary Chinese citizens living their daily lives in a tiny corner of East Asia_-provides the perfect opportunity to observe, listen, and think about cultural differences.

How do students studying in other countries respond to the cultural differences they inevitably encounter? How do they make sense of their surroundings, such as an open-air bike shop? What are they thinking and how do they respond when local customers' broken bikes take precedence over theirs?

The focus of this essay is how people respond to cultural difference, and, specifically, two tendencies. One tendency is to romanticize the cultural differences encountered. Another tendency is to rush to a negative judgment about the specific people involved, and about their culture more generally. In this essay, I illustrate these tendencies by analyzing the difficulties my students, my family and I had adapting to Chinese culture, and by drawing on examples from my own previous experiences. I then propose a third, contrasting mindset that involves suspending judgment in order to better understand and appreciate cultural differences. This third way fosters other-regarding travel. My aim is to help students make the most of their cross-cultural experience by suggesting 
ways they might learn to appreciate cultural differences, gain heightened selfunderstanding, and foster good will among their in-country hosts.

To differing degrees, my eight study abroad students, my family and I struggled to adapt to Chinese culture. We, and many of the Westerners I met, routinely complained about different aspects of Chinese society. I alternated between being frustrated at their negativity to being intrigued by it. In the end, intrigue won out and I spent considerable time wondering why Westerners were struggling to adapt to Chinese life. This question inspired me to attend more closely to the ways they responded to cultural differences. In addition to intently observing our behavior, I kept notes on how we responded to critical cross-cultural incidents. The patterns of response to cultural difference that emerged after rereading and analyzing my notes form the basis of this essay.

The individual actions in the examples that follow, while based on actual incidents, represent responses to cross-cultural differences. Pseudonyms are used to protect student privacy, but far from exempt myself, I offer as examples some of my own cross-cultural blunders.

\section{Rom anticizing CuItural Differences}

Some students romanticize cultural differences, particularly during the early stages of a cross-cultural experience. In some cases, dissatisfaction with important aspects of their home culture motivates their travels. Many of these students are also determined to avoid ethnocentrism. Often, they tend to overcompensate, and instead idealize the cultural differences they encounter. Initially at least, these students conclude that the host culture is particularly virtuous, and they lament that everyone would be better off, "if only more people lived like" their host culture.

In China, my family, some of the students, and I routinely lauded the Chinese culture for several qualities, including grandparents' involvement with their grandchildren, the vibrant street life and sense of community Chinese citizens seemed to enjoy, the sense of personal safety that prevailed, the inexpensive cost of living, and peoples' resourcefulness. An example reveals the limits of this idealizing orientation.

My family and I and some of the students were impressed by the strong sense of community that prevailed on campus among the students, and among all the residents including faculty, staff, their children, and retired university employees. The campus streets and sidewalks were always overflowing with people, many walking hand-in-hand or arm-in-arm, smiling, talking, seemingly enjoying themselves. Classmates squared off against one another in 
endless soccer and basketball games. Other students played ping-pong and badminton. Often, retired university residents sought out open spaces to practice tai chi together. Still others bicycled, flew kites, played mahjong, and walked their small dogs. The contrast with typical US suburban communities was striking. In many cases, we reflected, few, if any, people are found outside in the US neighborhoods in which we live, and even when they are, they most often engage in solitary activities like walking and gardening. Any observer would be hard-pressed to find a downside to the Chinese emphasis on close social relationships.

Over time, however, we found other sides to the wonderful cultural virtue of friendship and deep sense of community. The first clue that things were more complicated than they first appeared came early one February morning when a screaming infant awakened us. We grasped that the screaming was coming from the apartment next door, and realized the distraught two- or three-year old was on the move. We could tell from the wailing that she had walked down the alley and around the corner. The piercing cries moved my wife to intervene. After quickly dressing, she hurried off in the direction of the screaming infant. Through early morning darkness, several hundred yards from our apartments, she spotted the infant and approached her. But, the hysterical child didn't want to be held, so Lynn tried to get a passing student or another adult to help. To her surprise and dismay, the first three or four students she asked for help refused to lend a hand. Finally, she cajoled two female students to help. The distressed infant let one of them pick her up, and gradually calmed down. At that point, Lynn escorted the students and child back to our apartment building. The students left Lynn and the child at the door. Eventually, an equally-distressed mother came to the door, grabbed the child, and pulled her into the apartment, without even making eye contact with Lynn. When the incident was over, we were taken aback by a seeming lack of concern on the part of passers-by for the welfare of the upset, wandering child, especially in a community whose close relationships we had praised so highly.

The point of this example is to illustrate that the cultural differences that often appear virtuous at first glance, may not be exceptional upon closer examination. The experience with our distraught infant neighbor, along with other incidents, caused us to rethink our initial, romanticized thoughts about our Chinese neighbors' community-mindedness. Although the experience didn't completely negate our appreciation of the value for many Chinese of interpersonal relations, it prompted questions about how truly connected people were to one 
another. How deep were their bonds? How substantive was the sense of community? While we were left without definitive answers, the questions kept us from further romanticizing other cultural differences we encountered.

\section{Rushing to Negative Judgm e nt s}

If one tendency of some students studying in other countries is to romanticize the cultural differences they encounter, another tendency is to rush to a negative judgment about the people involved in the cross-cultural encounter and the culture more generally. These turns towards negative judgments have three roots: a traveler's subjective perspective, the misreading of cultural cues, and predisposed expectations of "the way things should be." Several examples illustrate this.

As a part of my daily routine, I visited an Internet café to read Western newspapers and communicate with colleagues, friends, and family. The highspeed Internet connection that enabled me to connect to the outside world for $25 \not \subset$ an hour kept me coming back to the dark, dirty, smoky cyber-cave. My fellow Internet users were mostly university-aged young men who surrounded their keyboards with some subset of the following accessories: Coke can, cell phone, bowl of noodles, cigarette lighter, and pack of cigarettes. The most memorable aspect of life inside the Internet café was the incredibly high percentage of young men that were chain-smokers.

"How dumb," I thought, "they're killing themselves." "What's wrong with these people?" I wondered, "This is a lung cancer pandemic in the making." In asking what was wrong with these people, I intimated that the male smokers surrounding me weren't very smart. In turn, that thought process contributed to negative judgments about Chinese citizens more generally. "Why aren't the Chinese more health conscious?" I wondered. And one afternoon, after sitting next to a chain-smoker, I thought, "It's one thing if he wants to endanger himself, but it's the height of rudeness to subject me to the same pollution." Again, I wondered, "What's wrong with these people?"

The most egregious flaw in my thinking was categorizing all Chinese as dumb, not health-conscious and rude based exclusively upon a few negative encounters with a few chain smokers in one tiny corner of an expansive country. I had rushed to my negative judgments. I didn't stop to question the underlying causes of why so many men smoke. Nor did I bother to ask whether my own country's tobacco and advertising companies contributed to the high incidence of smoking. I didn't take the time to consider the fact that many Chinese citizens have more disposable income than in the past primarily because 
the US and other Western countries import so many goods from China. In reacting so quickly and so negatively to my smoke-filled environment, I didn't take the time to think about whether my fellow Internet café inhabitants should be free to choose how to spend their surplus income, making choices as people elsewhere have been doing for ages. At present, many Chinese are reveling in having more choices-choices about whether to smoke or not, choices among restaurants, choices about vacation destinations, choices among cell phone plans, and choices about entertainment - that many people in Western countries take for granted.

It took more time to realize that my perspective on second-hand smoke had been shaped by my experience as a US citizen in the second half of the 20th century. In the end, the person next to me in the Internet café is free to smoke and even exhale his smoke into my face if he so chooses. Whether I decide to stay seated or to leave, the burden is on me, as visitor and guest, to adjust to his smoke-filled environment.

In the previous example, I rushed to negative judgments about Chinese citizens primarily as a result of my subjective and parochial worldview; other times, however, we rush to negative judgments simply because the cultural difference at hand isn't what it appears to be at first glance. These mishaps are simply cultural misunderstandings.

As an example of this phenomenon, consider an incident during a trip to Accra, Ghana, to visit students studying at Cape Coast University. Over the course of a two-week visit, Dave, a former colleague, and I became friends with Marshall, the Cape Coast University employee who had been assigned to us as our driver. The more I got to know Marshall, the more I liked him. He had held a series of interesting jobs in a few different countries, he had a large and loving family, and he was excited about the goings on at his local church. I could tell by the way he talked about his family that he was a caring father. These positive impressions were all called into question when, while negotiating narrow streets in a dense, residential part of Accra in our van, an 18month old child ran out into the street right in front of us. Marshall slammed the breaks, stuck his head out the window, and yelled at the knee-high girl in a local dialect. I was stunned. I thought I knew him well enough to know he wouldn't cruelly lash out at a young child. The three of us sat in silence for a few minutes until Dave, sitting in the passenger seat, asked, "What did you say to that girl back there?" Marshall briefly paused, and then said, "I didn't say anything to the girl. I yelled at her mother telling her 'Children are precious gifts from God and you should keep a closer eye on yours!” 
This cultural misunderstanding was an epiphany for me. I learned that cross-cultural encounters aren't always as they first appear; as a result, when trying to make sense of them, we should avoid reaching quick and definitive conclusions. I was certain that I saw and heard Marshall yelling at an infant. In actuality, I couldn't see Marshall's eyes from where I was sitting to know who he was looking at, and I couldn't understand what he said because I didn't understand the local dialect. Sadly, I didn't let those limitations keep me from concluding that Marshall was not a caring person. When trying to understand cultural differences while living abroad, our eyes, ears, and other senses sometimes fail us.

Even our own sense of cultural competence, developed through a lifetime of fairly predictable daily activities, can lead to negative judgments about a host culture. At home, we learn how to accomplish things, and this creates expectations about "the way things are supposed to be done." When living in other countries, these expectations complicate our efforts to adapt to different ways of completing daily activities. My observations of one student's experience renewing his visa illustrate this point.

After a day hiking with my students, an aggressive monkey scratched one of them, Matt, on the nose. Fearful of rabies, we immediately took Matt to a medical clinic, where he had the scratch cleaned and received several shots. We learned later that evening that Matt also needed a gamma globulin shot within 24 hours. But the next morning we found out that the serum was not available locally. After a phone call to a travel agent, a dash to the airport, a flight to Hong Kong, a train ride from the airport, and a taxi ride to the recommended hospital, Matt received the gamma globulin shot within the allotted timeframe. The trip to Hong Kong, however, meant that our "single entry" visas were now expired. Although we were able to get new 30-day tourist visas issued in Hong Kong, we would have to get them renewed four weeks later, back in Chengdu.

A few days before our 30-day visas expired, Matt and I headed out with documents, passports, visa pictures, and money. Early on in the day, it became obvious that Matt, whose patience and travel sensibilities I had been impressed with in Hong Kong, was not prepared for the bureaucratic obstacles we would have to hurdle. For some reason, in the intervening month, his pleasant, easygoing attitude had taken a turn for the worse. Now, when confronted with cultural differences, he swore incessantly, rolled his eyes in disgust, and complained bitterly about the situation. Our tasks of negotiating Chinese bureaucracy with marginal language skills and Matt's negative mindset were a combustible combination. 
After exiting our taxi, we didn't know which building to enter. Naturally, we chose the wrong one, but we didn't realize it until a few workers pieced together the nature of our errand and then sent us to another building across the street. Once inside the correct building, we stood in a long line, only to learn that it wasn't a "Visa Renewal" line. After some confusion, we settled in to wait in the correct line. Once it was our turn, the interaction with the young, uniformed bureaucrat was strained. She seemed irritated that we needed a little help in filling out the visa applications correctly. She also informed us we each needed an additional photo, we would need to return in five days to pick up our new visas, and we needed a different category of visa than we thought; as a result, they were going to cost more than we had anticipated.

Matt swore and fumed once we left the building, "Why didn't Rongli [the program's Sichuan University liaison] tell us we needed two pictures! Why didn't she come with us!" In my reflections at the time, I wrote, "Matt was mad at everyone and everything." In the end, he was upset with Rongli, he was still upset that the first taxi driver didn't automatically point the right building out to us, he was upset that the inside of the visa building wasn't easier to negotiate, he was upset that we needed a more expensive type of visa, and he was even upset at the return taxi driver for getting stuck in downtown traffic.

Before traveling across town with Matt, I had taken some time to think about what could go wrong. I knew from similar experiences in the past that it was going to be a long and trying morning and that patience was going to be essential. Our difficulties didn't fluster me because I had anticipated problems. One problem, Matt's impatience and mounting anger, did catch me off guard. As the morning's challenges mounted, Matt grew increasingly upset. During our return taxi trip, I snapped, "We're visitors! They make the rules! We're at their mercy!" "Yeah, but," came a weak reply, but I continued, insisting, "Complaining isn't going to change anything!" Of course, my outburst didn't change much either. Matt's negative attitude increased and he struggled with cultural differences throughout the semester.

For Matt, everything about the morning's frustrations was abnormal. His sense of "the way things are supposed to be done" was tested at every turn. Although all we both could do was try to piece things together by watching others; I anticipated this, Matt did not, and that made all the difference in how we coped with the challenges.

Expectations about the way things are supposed to be done also had an impact within the academic experience. For most of the students, last-minute schedule changes were a source of frustration throughout the semester. At US 
colleges and universities, the "Schedule of Classes" that universities publish, course syllabi, and even individual calendars that plan meetings and events weeks and months in advance, have become almost part of the natural order. Given this context, the students wanted to know the logistical details of their class schedule shortly after arriving on campus. Chinese institutions do not organize classes in the same way. The students struggled to adapt as Rongli continued piecing their schedules together, right up until the semester began.

Gradually, I came to accept the different way most Chinese managed time. I found it easier to adapt to Rongli's and other Chinese peoples' spontaneous decision-making after Rongli explained that spontaneous decisionmaking even frustrated her at times. Specifically, she related how she sometimes arrived at work only to learn that her work unit has selected her to attend a banquet that same evening on behalf of the unit. Instead of viewing spontaneous decision-making as some type of flaw in the Chinese character, I came to accept it as not better or worse than to what I was most accustomed, but just another cultural difference.

To summarize, through numerous examples of cross-cultural encounters, I've illustrated two common tendencies, romanticizing the cultural differences encountered; and rushing to a negative judgment. The ways in which the examples overlap identify problematic patterns and themes. By better understanding what tended to go wrong, we will be in a better position to move towards other-regarding travel.

\section{Wh a t w e n t W r ng-Limitations a $\mathbf{n} \mathbf{d} \mathbf{h}$ e m e s}

Examining these examples reveals three elements that made it difficult to negotiate thoughtfully and successfully the cross-cultural encounters that filled our days. Ultimately, our limited communication skills, our unconscious and subjective sensibilities about "the way things are supposed to be done," and our misreading of unfamiliar cultural contexts, caused us to rush to negative judgments.

An admittedly Western way to think about these three elements is as a logical equation: our limited communication skills combined with our subjective sensibilities combined with our misreading of unfamiliar cultural contexts led to premature negative judgments. In short, three causes lead to one negative effect. However, this linear conceptualization doesn't honor the complexity and fluidity of the cultural adaptation process. In actuality, the problematic patterns interact and overlap in ways that defy simplistic characterization. Each contributes to the other in ways that are synergistic. For example, one of the elements, our 
limited communication skills illustrates this point. Obviously, it's preferable for foreign visitors to know the hosts' language, and even more ideally, for all of us to know one another's languages. However, even bi- or multilingualism, in and of itself, is not a panacea for enlightened cross-cultural interactions and understanding. The bilingual visitor still must contend with his or her subjective worldview and the limits of their eyes and other senses in providing cues for unfamiliar cultural contexts. For this reason, even competent multi-linguists may still, on occasion, rush to negative and unwarranted judgments about their host culture. An alternative travel orientation would balance the multiple factors in these encounters.

\section{Crafting other-Regarding Trave I}

Other-regarding travel emphasizes cultural differences as opportunities for heightened self-understanding and fosters good will rather than ill-will among locals. Rather than discussing other-regarding travel as an abstract concept, it is more helpful to begin thinking about it by detailing the thought processes and attributes of students and others who embody it.

\section{Other-Regarding Travelers are Conscious of their Limitations}

With respect to attitudes, other-regarding travelers are aware of their limitations and how those limitations tend to confound cross-cultural interactions. They reflect on their own role in challenging cross-cultural incidents.

Despite the spread of the English language, they don't expect their hosts to know English or to use it with them. In China, some students complained when a favorite Western-oriented restaurant didn't have waiters or waitresses who knew enough English to correctly fill orders. So when the students ordered one type of pizza and occasionally received another they grew exasperated and whispered bitterly, "They should require their employees to know some English." In contrast, the other-regarding traveler appreciates when someone is conversational in English, but doesn't expect it. They understand that they bear the responsibility to learn to communicate better with their hosts. They know that if they are slow to learn, or fail to learn their hosts' language altogether, they relinquish their right to complain about things like restaurant menu mix ups.

Similarly, other-regarding travelers are conscious of how their subjective sense of "the way things are supposed to be" complicates cultural interactions. They understand their perspectives of "ordinary" smoking etiquette or "normal" course schedules are culturally defined. They reject fixed notions of 
ordinariness and learn to view normality as an ambiguous and dynamic concept. They accept that people in other cultures have different ways of conducting their lives, ways that work well for them. They guard against ethnocentrism by learning to interpret cultural differences in the larger cultural context.

Also, other-regarding travelers are cognizant of the fact that sometimes there is more to understanding a challenging cross-cultural interaction than their eyes, ears, and other senses are able to process. Consequently, they guard against rushing to negative judgments about the people involved and the host country. In short, patience and humility distinguish other-regarding travelers who are mindful of how these three limitations often exacerbate cultural misunderstandings.

\section{Other-Regarding Travelers are Mindful of their Visitor Status}

Other-regarding travelers embrace cross-cultural differences as integral to their experience and approach living abroad as an opportunity for heightened self-understanding. They do not expect their hosts to change behavior for them.

Ultimately, this way of thinking prompts important questions about students' reasons for traveling abroad in the first place. Sitting in the taxi with Matt, I couldn't help but wonder why he had decided to spend the semester studying in China. I wondered, if he wanted to be able to complete an errand with the same efficiency and predictability as at home, why didn't he stay home? Some of my students admitted to not having thought very carefully through the reasons for going. One student acknowledged being motivated mostly by her friend's decision to go. Some students are motivated to study abroad to strengthen their graduate school applications or to improve their job prospects. Absent some intrinsic motivation related to personal growth, students tend to succumb to a negative, self-regarding travel orientation.

Ideally, students studying abroad should expect to return changed in important ways. The prospective traveler should assess whether they are approaching their sojourn with a spirit of reciprocity, meaning they anticipate being positively transformed by their hosts far more than they will change anyone with whom they study or live.

\section{Other-Regarding Travelers are Inquisitive}

Other-regarding travelers constantly ask questions about what is happening around them and why. Genuine, open-ended questioning serves at least two important purposes. First, it helps guard against the inclination of some visitors to romanticize cultural differences. Recall the questions my 
family asked about our Sichuan University neighbors' bonds and their sense of community. Those questions, and that inquiry helped us from romanticizing what on the surface appeared to be a profound sense of community. Second, in making sense of cross-cultural encounters, authentic, open-ended questioning may be the best way to guard against the tendency of visitors to rush to negative judgments. These questions serve as conceptual checks against ethnocentrism.

\section{I m p I c a tions for Practice}

What might these examples and ideas mean for study abroad program design and implementation? Two caveats before offering some implications for practice: first, there are many ways to cultivate an other-regarding travel orientation in students. It would be presumptuous to offer prescriptive proposals to international educators that work in unique institutional and international settings. Consequently, the following proposals are what I would recommend to my own university, given the chance to shape its study abroad programs. Hopefully, other international educators will adapt these recommendations to meet the unique needs of their students. Second, cultivating an other-regarding travel orientation in students is a nuanced, long-term process that requires more from students than overly simplistic travel abroad "dos and don'ts" suggest.

As soon as students express interest in a program, international educators should begin promoting an other-regarding travel orientation. One important pre-departure strategy is to have students articulate their reasons for wanting to study abroad. Students traveling to developing countries should go expecting to be challenged and changed in unforeseen ways. Undoubtedly, a student's frame of mind is more difficult to assess than their grade point average, but ultimately, more important.

The ability to evaluate a situation or facts from another person's or group of people's point of view is an essential part of developing an other-regarding travel orientation. International educators should make sure each prospective student has at least rudimentary perspective-taking skills. Consequently, prospective students should provide an example of a time in which they have evaluated a situation or facts from another person's or group of people's point of view. Conceivably, students could submit a completed class assignment, describe a relevant anecdote in an application essay, or provide examples in interviews. Faculty references should specifically address the relative quality of prospective students' perspective-taking skills as well. 
Also, before students commit to going abroad, they should be asked whether they are willing to reflect upon, write about, and talk with their peers about cross-cultural difficulties they will inevitably encounter. Normally, I am wary of unilaterally-derived requirements that are assumed to be in students' best interests, but based upon my recent experience in China, I feel this expectation should be a prerequisite of participation. To help students understand the expectation, exemplary models of this type of work, preferably models written by previous students, can be provided. The more students understand this expectation is intended to spark other-regarding ways of thinking and heightened self-understanding, and the more convinced they become it is integral to their experience, the better.

Students can quicken the process of developing other-regarding sensibilities by working together on the following activities. Specifically, I recommend site directors host a weekly or bimonthly group meeting or "cultural conversation" where a few different participants take turns each session sharing their cross-cultural stories. At meetings where they're not scheduled to present, students should carefully listen to their peers, and afterwards, pose questions or offer thoughts to extend the presenters' thinking. Site directors should challenge and encourage students to extend themselves, befriend locals, travel on their own, and experience different aspects of the culture.

Site directors should impress upon students the inevitability of challenging cross-cultural incidents, and can help students understand those frustrating experiences as important learning opportunities. Specifically, students should be asked to select a particularly irritating experience or interaction to reflect on, write about, and share with others. In addition to describing their challenging cross-cultural incident, students should deliberately and carefully analyze them. The aim is probing, purposeful, directed personal journaling although students could conceivably communicate their thinking in non-narrative forms of expression including poetry, drawing, photojournalism, or drama. Towards this end, the following questions are helpful as catalysts for analysis and reflection:

1) Did my communication skills contribute to the cultural misunderstanding?

2) Did my sense of "the way things are supposed to be" contribute to the cultural misunderstanding?

3) Is it possible my eyes, ears, and other senses somehow failed me?

4) Was I sufficiently conscious of my visitor/guest status or did I expect my hosts to accommodate me by adjusting their cultural practices? 
5) Did I rush to an unduly harsh judgment about the people involved and did I overgeneralize it to the rest of the population?

6) What alternative interpretations of what transpired, from the perspective of my hosts, are possible?

7) How and why might what have happened make sense from their perspective?

The cultural conversations proposed here need not be overly serious or somber exercises in introspection and self-flagellation, but instead, safe, purposeful, encouraging, and at times humorous sessions intended to promote personal and group introspection and growth. As site director, I organized a few meetings that contained elements of these recommendations. For example, we had talent shows that were successful in creating a sense of community. One student performed trip-related Haikus, a few presented a Chinese dialogue, another read trip-inspired poems. Most memorable about the get-togethers was the silliness and laughter that punctuated the evening. I also provided optional meetings for group discussion to help students contend with sporadic concerns including a violent, mentally ill student in the international dorm, the outbreak of the Iraq war, and the outbreak of SARS. Those sessions were not well-attended. Some students said they were too busy for any meetings, but my sense was that more likely they didn't see the value of the meetings.

These cultural conversations, should take no more than an hour. The more students take the responsibility for running them, the more effective they will be. Ideally, once the site director develops a presentation schedule, his or her primary role should be timekeeper, starting the meeting on time, providing presenters with equal amounts of time, and ending on time. Those responsibilities could eventually be delegated to students. The role of nonpresenting students is to listen carefully and pose questions intended to deepen each presenter's thinking. The site director should take an occasional turn by presenting an analysis of a challenging cross-cultural incident. The site director's modeling of the process will help the students develop their own other-regarding travel orientation.

Lastly, "Post-Study Abroad Seminars" should be offered on the US campus for students returning from different locations to compare and contrast their experiences with reentry and continue processing their experiences. Seminar leaders should facilitate discussions among the students and provide feedback, as they strive to synthesize what they learned about cultural differences, 
an other-regarding travel orientation, and themselves. Again, these should be conversations where students learn as much or more from one another as they do from the faculty leader. As a culminating activity, students should submit their most thoughtful writing on cultural differences and other-regarding travel sensibilities. Completing a cycle, the most illuminating of those narratives should be shared with prospective students, and submitted to student-based publications both on- and off-campus.

\section{Conc I u s i o n s}

I've illustrated two ways students often respond to cultural differences, to romanticize cultural differences encountered and to rush to negative judgments about individuals and the culture more generally. The alternative is an other-regarding approach that emphasizes suspending judgment in order to better understand and appreciate cultural differences. Students who adopt this type of orientation are conscious of how their limited communication skills, how their subjective sense of "the way things are supposed to be," and how their senses sometime contribute to cultural misunderstanding. They are mindful of their status and know it's unrealistic to expect their hosts to change ingrained behavior on their account; maybe most importantly, they are inquisitive. They continually reflect on questions that help them suspend judgment, better appreciate their hosts' perspectives, and avoid impulsive ethnocentric conclusions.

In my own experience, living, working, and studying in Mexico, Ethiopia, Kenya, Ghana, and China profoundly and positively shaped my worldview. My personal commitment to pluralism and inclusion, guarded views of nationalism and materialism, belief in the equality and dignity of the entire world's people, my cross-cultural sensibilities, and my commitment to global citizenship are all traceable to those pivotal experiences. Yet I realize that an other-regarding orientation grows with slow but steady progress with each intercultural experience, a journey incremental in nature. I suspect it takes a lifetime to cultivate the true spirit of reciprocity upon which other-regarding travel is built. My hope is the ideas presented here somehow help foster that spirit in others, advance other-regarding travel, and help students be more thoughtful and respectful. 